\title{
English as an Academic Lingua Franca ${ }^{1}$
}

\author{
Pamela Faber \\ University of Granada \\ pfaber@ugr.es
}

\begin{abstract}
In today's world, the European Union is searching for a delicate balance between linguistic integration and diversity. Thanks to international knowledge transmission and exchange as well as co-operation and mobility beyond national boundaries, English has now become the preferred option for linguistic unity. It is a language that allows native speakers of different languages to communicate. However, the use of English as a lingua franca should not (and does not) threaten plurilingualism in Europe, as reflected in the many national languages in Europe and the relatively peaceful coexistence of national and minority languages in many European countries. In fact, English, as used for international communication purposes, complements and supplements national languages.
\end{abstract}

\section{Introduction}

In 1999 NASA lost a \$125 million Mars Orbiter. The spacecraft was destroyed by atmospheric stresses and friction, and was transformed into a blazing fireball. The reason for this disaster was faulty communication. A Lockheed Martin engineering team used imperial units of measurement (pounds-seconds) while the agency's team used the more conventional metric system for a key operation. The units mismatch prevented navigation information from transferring between the spacecraft team in Denver, Colorado and the NASA flight team in Pasadena, California.

The imperial or English measurement system could be compared to the national language of a country, and the metric system to a numerical lingua franca, or world system of measurement, which should have been used by both parties, but was not. In the case of the Mars Orbiter, the use of the same code would have prevented an extremely expensive disaster. 
This is just one of many cases in which communication breakdowns have occurred because the discourse participants were not using a common system to transmit their message.

Without a doubt, both in numbers and language, communication would be infinitely easier if everyone were able to use the same code, especially in certain contexts where misunderstandings are very costly in terms of money and/or time. Even without the risk of a catastrophe, a common language or lingua franca is advantageous because it is a powerful vehicle for knowledge transfer, which greatly facilitates cross-fertilization in all knowledge areas. In the European university system, an academic lingua franca for international communication and understanding is necessary.

Thanks to international knowledge transmission and exchange as well as co-operation and mobility beyond national boundaries, English is well on its way to becoming the preferred option for linguistic unity. It is a language that allows speakers to communicate when their primary languages do not coincide. Furthermore, the use of English as a common language or lingua franca should not (and does not) threaten plurilingualism in Europe, as reflected in the many national languages in the European Union and the relatively peaceful coexistence of national and minority languages in the same country. In fact, English, as used for international communication purposes, complements and supplements national languages (House, 2003).

\section{Language for identification vs. Language for communication}

Now, in the 21 st century, the world is shrinking and is becoming an increasingly smaller place. In today's society, people travel more often than before, and often find themselves immersed in contexts in which they need to communicate with others who do not speak their same language. This means that both speakers are obliged to seek a third language, which is different from the primary language of either party. This third language, rather than a cultural artefact, is merely a convenient tool, with no national or cultural implications for the speakers.

This sort of context highlights the crucial difference between a language for communication or lingua franca and a language for cultural identification, which is a national language linked to the speaker's culture (Hüllen, 2003). A lingua franca, on the other hand, simply is there to fulfil a specific need, and thus, is not in competition with any national language.

People use language for a wide variety of purposes. People have a native language to affirm their membership in an ethnic group. For example, when travelling in a foreign country, tourists immediately reach out to other travellers, whom they would not even look twice at in their own countries, merely because they hear them speaking the same language. They latch onto them as they would to a life raft in a stormy sea, since these anonymous travellers offer a tiny island of sanity where they can speak and be understood.

Although Europe defines itself as a Union, it is divided by language. Within the European Union, one only has to travel a relatively short distance before one ceases to be intelligible. This does not happen on the continents of North America and South America, 
for example. The hope exists, of course, that language barriers can be eradicated to some extent by increasing the importance of foreign language training in European schools. Nevertheless, even though the plurality of languages spoken in Europe should be respected, it is fairly unrealistic to believe that within the next decade all Europeans will suddenly acquire the ability to speak several languages in order to be able to communicate with citizens in other member states. A more realistic view would be to take advantage of the generally acknowledged status of English as an international communication tool.

Without any type of official declaration or sanction for the role, English has become the "de facto" language of communication for those who wish their oral or written texts to travel beyond national boundaries. This is certainly the case in international conferences where scientific and technical information is presented and exchanged.

English as a lingua franca (ELF) is a term that has been coined to designate this new language variety, which overlaps, but does not totally coincide with English as a national language and cultural vehicle. This English for reference and communication purposes has become a variety in its own right, and its speakers are not regarded as language learners (which implies deficiencies), but rather as language users, who are in the process of creating their own standards of acceptability, comprehensibility, and correction.

In most cases, English is not the mother tongue of ELF speakers. As is well known, English is a primary language of identification for people in the United Kingdom, the United States of America, Canada, Australia, New Zealand and several other countries, where English is either an official or co-official language. However, in the world today, about ninetenths of the speakers of English are not native speakers, and thus, feel no cultural affiliation with this language. They merely use the language as a means to reach a wider, more international audience.

This use of English in a variety of specialized communicative contexts has irrevocably changed the language, making it more dynamic and flexible and much less standardized, with a greater focus on transmitting messages rather than strict grammatical correction. These considerations have changed the perceptions of those who operate with notions of deficit linguistics as background (Graddol, 2001).

A great many non-native English speakers use ELF in an extremely dynamic way that infuses vitality in its vocabulary and syntax (e.g. prepone as an opposite for postpone in Indian English). In research English, standards of acceptability have also changed since the style in research articles is gradually becoming less formal and ponderous. Even the structure of noun phrases has varied. For example, in Standard English, the noun phrase, system analysis, refers to the analysis of systems even though system is singular. (The reason for this is that system is a noun that is playing the role of an adjective.) However, ELF in science and technology has changed that, and now systems analysis, which emphasizes the plurality of system, is also acceptable and appears in many specialized texts, even though, strictly speaking, it does not conform to conventional grammatical standards. In fact, one might say that grammatical correctness has taken a backseat to successful and efficient communication.

In contact situations, ELF is used as a "native-culture-free" code (Pölzl, 2003) that allows its users to create their own temporary culture. Examples of this type of context are 
conferences and international meetings, and even scientific journals. These situations are breeding grounds for temporary, self-contained cultures, specific of a certain professional group. The use of the same type of discourse and terminology affirms the speakers' identity in a certain profession (industrial engineers, computer scientists, health professionals, astrophysicists, etc.). The terminology in a specialized field represents the knowledge structures characteristic of the area. In this sense, the relation between specialized knowledge content and the language used to express it is very close. For example, a mastery of technical language in a certain area is generally perceived by others as mastery of the knowledge represented as well.

The fear once existed in some circles that this more flexible use of English would have negative effects. Native English speakers feared that it would cause their language to deteriorate. Speakers of other languages were afraid that it would lead to linguistic globalization and a general rejection of other national languages. However, this has not occurred. Indeed, in many cases, the use of English in contexts of international communication has even reinforced and reaffirmed the use of the national language within the country (Alcón Soler, 2007). English becomes a medium that permits the communication between discourse participants who would otherwise have to resort to translation.

\section{Why English?}

However, one might indeed ask why it is that English has become the chosen language for international communication. As languages go, Chinese, Arabic, Hindu, and Spanish are also spoken by a great many people. It cannot be because English is a superior language. Objectively speaking, no language is inherently better or worse, easier or more difficult, more coherent or incoherent than any other. In fact, every speech community ever studied, no matter how 'primitive' in cultural terms, has a fully developed language, with a complexity comparable to those of the so-called 'civilized' nations. As a result, there are no Bronze Age or Stone Age languages. All languages have a complex grammar. A relative complexity in one respect (e.g. no word position) is compensated by a relative simplicity in another (e.g. lack of word endings).

Consequently, English has not acquired a pre-eminent position in international activities, such as science and technology, because of any type of inherent linguistic merit. It is not so much a question of the number of speakers that a language has as the activities (both professional and socio-cultural) that a language is used for, which is the gauge of a language's perceived importance.

Indeed, in no other knowledge area is the use of English more widespread than in science and technology since research must be suitably presented and marketed in this language in order to receive sufficient research funding. In the world today, this means that the research must not only be described in English, but the resulting text must be clear, convincing, and understandable.

University of California scientist, Dr. John Roth, speaking at an international conference, discussed the fact that bacteria and phage laboratories were becoming increasingly 
marginalized at many universities, despite their still powerful role for explaining molecular mechanisms. He claimed that the tendency to describe research in overly complicated and abstruse terms was mainly responsible for this tendency. According to Roth, the reason for the marginalization of this research line was as simple as the failure to communicate science appropriately and persuasively (Johnson, 2005).

However, there are other issues at stake here besides selling one's research to funding organisms, which make the use of English important. As we all know, in areas such as engineering, experimental science, telecommunications, etc., research findings must be published quickly or not at all. As in the early days of the Gold Rush in California, it is necessary to stake one's claim immediately at the gold mine and ride into town to obtain a deed of ownership. If this is not done quickly, someone else (a claim jumper) will arrive, discover exactly the same thing, and take credit for it.

In a wide variety of fields over the years, there has doubtlessly been a huge body of extremely valuable research in other languages, such as Chinese, Polish, or Russian, but, internationally speaking, few people in the international research community were able to read these texts. These scholars doubtlessly proposed many of the same theoretical premises so successfully proclaimed some years later by authors in Massachusetts, London, or California. Who received the credit? Not the authors who said them first in their native language, but rather those who submitted their articles to scientific journals with a wide distribution, and published them in English. In the world today, it is no longer only a question of saying something first. It is also a question of saying it first in English.

This even applies to inventions that were discovered long ago. For example, the design and construction of the first modern submarine has been attributed to various inventors (mostly Americans who participated in the American Civil War in the 1860s). Only recently is another name being mentioned, that of Narcis Monturiol, a Catalonian inventor who in 1859 built the most advanced underwater vessel of the day. Most people were unaware that he even had done this until his American grandson who went to Princeton and obtained a $\mathrm{PhD}$ from Oxford, wrote a book (in English) about his grandfather's invention (Stewart, 2004).

Often timely communication (even many years after the fact) is what makes the difference between receiving credit for a new idea and not receiving credit for it. In today's world this means describing research in English.

\section{The European Union and language policy}

The European Union has no common language policy since sovereignty in this area belongs to each member nation. Nevertheless, European Union institutions try to encourage cooperation between the member states, and do their best to promote the European dimension in the language policies of member states. In this regard, the EU encourages all of its citizens to be able to speak two languages in addition to their mother tongue through a number of funding programmes specifically designed for language learning. Still and all, these measures do not seem to be particularly effective, at least on a short-term basis. 
Multilingualism remains the exception rather than the rule, and is only pervasive in countries such as Denmark and the Netherlands, whose populations must learn other languages if they wish to converse with anyone outside their national borders.

The EU has quite understandably been reticent about officially sanctioning the use of one language over the others. This is hardly surprising since nations and speakers are enormously protective and defensive of their national language. Although most recognize the need for proficiency in other languages, they do not wish for one language to be used in preference to another language (unless it happens to be their own).

As a compromise, Esperanto has been proposed as a pivot language for the European Union translation services, or even as a common international language (Phillipson, 2003). Since Esperanto has no cultural identity, and does not belong to any nation in the world, its generalized use in an international context would not offend anyone. Thus no one would have reason to feel slighted because their language had not been accorded a privileged status. Unfortunately, Esperanto has the disadvantage of not being taught in schools, of having relatively few speakers, and of not being used in scientific and technical communication at all. Even if it were officially designated as the world's language of international communication, this would not necessarily make it so. As ISO committees are well aware, the declaration of a standard does not always entail public recognition and use of the standard.

\section{English in European university teaching}

Within the context of European convergence and the creation of the European Higher Education Area, the use of English as a global language of communication, and as a teaching language in European university classrooms, has been and still is a topic of much discussion and debate. However, in order for European universities to be competitive there is a need for an academic lingua franca, which would facilitate communication beyond national boundaries and contribute to the acquisition and transfer of knowledge. Not surprisingly, the principal candidate for this lingua franca is English, which is the language currently being used in international business discourse as well as scientific and technical communication.

European universities began using English in the classrooms as a way of stemming the 'brain drain', and at the same time as a lure for international students. It was a way of pooling resources and creating international masters programs so that the best students would not be tempted to cross the ocean and go to universities and research institutes abroad. Englishmedium course programs are now mainly found in large multidisciplinary universities with both undergraduate and postgraduate programs in the Netherlands, the Scandinavian countries, and Germany. This state of affairs is in vivid contrast to universities in southern Europe (e.g. Spain), which offer relatively few programs in English.

In the Spanish context, one possible reason for this is that many tenured university professors find it difficult to give their lectures in English since they received their foreign language training in an era when language learning was not a priority, and French was the main language taught in secondary schools. However, now in Spain, as in other European 
countries, English has become the first foreign language taught though this is still a relatively recent event. Despite the evident advantages of multilingualism, foreign language education still lags far behind current needs.

Educational authorities in Spain, many of whom were raised in a not-so-distant era when foreign languages were not regarded as serious subjects at the same level as Physics, Math, and Science, still have a somewhat outdated view of foreign language teaching, foreign language teacher training, and language teaching methods. There is a lack of suitable material and human resources for foreign language education at the primary and secondary as well as at the adult levels. This sad state of affairs is only made more paradoxical by the naive declarations that surface every so often in the news, such as the affirmation made by the Andalusian Regional Government that all Andalusians will be trilingual in the next five years.

Although in Spain there is a certain reticence to giving university programs in English, this state of affairs seems to be timidly changing. For example, at the University of Granada, knowledge transfer in English is regarded as a quality factor and is encouraged. Professors who agree to give their classes in English are given a credit reduction on their teaching load. There are even a few bilingual masters programs, such as one in Environmental Hydraulics. In other universities in Spain there is also the desire to use English as the teaching language in a certain percentage of subjects in the new degree programs that are currently being implanted. This is very positive since it will attract students from other countries.

In reference to Europe, a recent study (Wächter, 2008) found that most English-medium university education is given, above all, at the level of Masters and $\mathrm{PhD}$ programs. Across Europe, the subject area in which English-taught programs are most frequently offered is engineering and technology (27\%), followed by business and management studies $(24 \%)$ and the social sciences (21\%). Together, these three subject area groups make up $72 \%$ of the total program offer. The subject-area distribution has changed remarkably since 2002 , when business and management led the second-ranked subject area, engineering by more than double, and the social sciences were only in fourth place. This gives an idea of how important English has become in the realm of science and technology.

\section{English in science and technology}

Practically all serious researchers in science and technology are now aware that they must have a good working knowledge of written and spoken English. The expanding network of shared knowledge means that engineers and scientists, who wish to be competitive, must transmit their ideas to the world in English, both in written and oral form. This necessarily entails having a certain proficiency in the language, which, if it was not obtained in childhood, has to be obtained as an adult.

However, becoming proficient in a foreign language as an adult in order to be able to present and transmit scientific and technical concepts (in both oral and written form) is not the same thing as learning the language in primary or secondary school, this adult type of communicative competence is different, nor are we even talking about the same variety of 
English. In general foreign language classrooms, the students learn a series of grammatical structures and a basic vocabulary that can be used for communicative interaction in contexts such as train stations, supermarkets, restaurants, and shoe stores.

Significantly fewer language courses target the language user who must interact in a specialized academic context. Necessary aspects of such a language course should take into account the fact that the students are adults, and have very specific language needs. These needs are not necessarily the same as those of the mainstream English learner, and must be acquired in classes with a small number of students, which is definitely lower than the groups of 75 to 100 students that proliferate at the university level.

Still another consideration is that university science and engineering students must know how to read articles and books in their chosen area in English, and be able to process the conceptual content, integrating it into their previous knowledge. This implies that they must develop rich knowledge structures linked to linguistic and terminological designations in English as well as their own language. Insofar as oral language comprehension is concerned, students must understand spoken English in order to be able to receive courses and seminars at an international level. The best way to accomplish this is for students to receive Englishmedium classes in their field of knowledge.

Another of the skills that students should attain is the ability to cogently and understandably describe their research, both in oral and written form, without boring their audience to tears. They must also know how to argue and defend their viewpoint at conferences or meetings with other scholars or scientists working in the same area. They must be able to get their point across by describing actions and events, manipulating objects, describing results, following a certain methodology, and reaching conclusions. These are skills that science and engineering students can only learn by doing.

However, what many aspiring ELF users of technical English do not realize is that spoken communication and written communication are quite different. The same rules do not necessarily apply. Speech is time-bound, dynamic and transient, whereas writing is space-bound, static and permanent (Crystal, 1997). In oral communication, the recipients are present, whereas in written communication, they generally are not. For this reason, many small communication gaps, which can be surmounted by gestures, facial expression, and linguistic creativity in oral contexts, become yawning chasms and abysses on paper or PowerPoint slides.

For example, written language is more conservative and has more rules than spoken language. People must approach the written word differently from the spoken word. This means the activation of different strategies. For this reason, those who speak as they write seem stuffy and boring, and those who write as they speak risk being judged poorly educated. A good speaker is not always a good writer, and a good writer is not always a good speaker. So what is the difference between the two?

\subsection{Spoken communication}

Contrary to popular belief, effective ELF spoken communication in international settings and events does not necessarily depend on being a native speaker or speaking with grammatical 
correction. It does depend on a number of other things, however, such as clarity, good organization, content relevance, voice tone, intonation, and generally anything that keeps the audience from falling asleep.

An experiment was carried out to discover possible problems linked to cross-cultural understanding in ELF communication. The subjects were speakers of nine national varieties of ELF from the United States and the United Kingdom, India China, Japan, and even Papua, New Guinea. Not only was no evidence found of a breakdown in the function of English as an international lingua franca because of the different geographical origins of the speakers, but, rather surprisingly, native speakers from the USA and the UK were not the most easily understood, nor were they as subjects found to be the best able to understand different varieties of English (Smith, 1992).

Speakers should be able to persuade readers that their work is worth listening to, and for that reason it must be presented in a dynamic and convincing way. This means varying speech rhythm and intonation, organizing ideas logically, and capturing the attention of the listeners. For example, PowerPoint slides, if used at all, should never be a reading aid for the speaker. The presentation should be legible with just the right amount of information for the audience to process, or it should not be used at all. Above all, one must know who one's audience is and have a good idea of what and how much they know. These are all commonsense factors that apply to the use of any language.

One must also be aware of the different types of interaction possible during a specialized communication event. An example of such an event is a conference in which research results are presented within a given knowledge field, such as telecommunications, earthquake engineering, architecture, nanotechnology, etc. Among the communicative interactions typical of an academic conference, one can find oral presentations, posters, round tables, plenary lectures, etc. However, even when these discourse types all contain and convey basically the same or similar information, the style, organization, and format of an oral presentation is hardly the same as that of a poster, which is different from that of a round table, which in turn differs from that of a plenary lecture.

For example, all of us have had to suffer through round tables in which the speakers did not seem to be aware that they were in a round table, and were not giving plenary lectures. Without respecting format, content type, and time restrictions, they talked on and on and on until the moderator had no choice but to cut them off. All of these academic discourse types in turn differ substantially from an article in a scientific journal, even when it describes the same research results that were presented orally at the conference.

The reason for this is that formal communication is constrained, and determined to a certain extent, by medium, format, style, and text type even when the communication act takes place in the same setting with essentially the same set of participants. The text type models the information conveyed as well as the language used for the presentation of the content.

\subsection{Written communication}

Research articles and reports fall into the category of written communication. In science and 
technology, describing research in written form is often not easy for engineers and scientists in any country, no matter what their native language happens to be. For this reason, practically all polytechnic universities and engineering schools offer courses in technical and scientific communication.

In European countries whose national language is not English, the difficulty is compounded since the course must teach English as well as aspects of written communication, such as sentence structure, paragraphing, connecting words, etc. Nevertheless, rarely is sufficient time allotted to this type of course even though communication in technical English should be a major block of program content. If the research of an engineer or scientist never transcends national boundaries, he or she might just as well be working in an impenetrable biosphere or air bubble. It is a case of the tree silently falling in the forest because no one is nearby to hear it crash to the ground.

In Spain, writing any type of text at all is a skill generally ascribed to the Humanities, and both scientists and engineers defend any problems that they might have in text production with the explanatory phrase: Es que soy de Ciencias. Loosely translated, it means that the speaker studied the science and engineering option in high school and at the university, and thus was not required to learn how to write in his native language, much less in a foreign language such as English. As a result, any errors in his/her text are totally justified. However, it is an educational gap that scientists and engineers inevitably pay dearly for.

Fortunately, this state of affairs seems to be changing. Technical writing courses in English are gradually becoming a priority in science and engineering programs in Spain since universities are beginning to wake up to the idea that their students also need to acquire this important skill. Part of the skill is learning how to organize content.

\subsubsection{Text format and organization}

As is well known, research texts are organized in such a way that their sections generally follow an idealized sequence of research development. This is the origin of the well-known acronym, IMRAD (Introduction, Methods, Results, and Discussion), which refers to the standard superstructure of research texts. Despite the fact that this is an Anglo-Saxon invention, other cultures have adopted it as well. Although it is generally thought that textual form is much more important in literature, it is also crucial in scientific and text, where it is also a vital part of the message conveyed.

\subsubsection{Good format but totally irrelevant content}

An eloquent example of just how important language, text format, and terminology are in scientific discourse as a means of lending authority and credibility (even to utter nonsense) is the famous spoof scientific paper, "The Endochronic Properties of Resublimated Thiotimoline", written by Isaac Asimov in 1948. The article, which describes experiments on thiotimoline, a totally fictitious chemical compound, has the format as well as all of the syntactic and semantic characteristics of a serious research article. It even includes charts, graphs, tables, and citations of fake articles in nonexistent journals. The results presented in 
the tables verify the patently absurd hypothesis that thiotimoline is so soluble that it dissolves in water 1.12 seconds before it even comes in contact with water.

Feinschreiber and Hravlek in their studies on the problem have contended that with increasing hydrophilism, the time of solution approaches zero. That this analysis is not entirely correct was shown when it was discovered that the compound thiotmoline will dissolve in water - in the proportions of $1 \mathrm{gm} / \mathrm{ml}$ - in minus 1.12 seconds. That is, it will dissolve before the water is added (Asimov, 1948).

Evidently, if the patently absurd assertion, formulated quite directly in the preceding quotation, had been made outside the context of a specialized scientific paper, and had not been backed up by an impressive display of (false) experimental results, it would have been questioned by anyone with a certain degree of common sense. However, despite the fact that the text was published in a journal titled Astounding Science Fiction, a great many readers were persuaded of the veracity of the information in the text, and subsequently requested access to the (nonexistent) journals cited in the article. Asimov's text was a perfect example of a scientific article in every way except for the fact that the information contained in it was absurd. It is also an example of how a suitable linguistic and textual context can make readers believe in the validity and reliability of textual content.

\subsubsection{Good content, but poor format}

Nevertheless, a more frequent situation is precisely the opposite. In other words, interesting research findings are often obscured by poor structure and format. Research results, which are important, can be incorrectly processed and evaluated by their audience because of an inadequate presentation. In extreme cases, this can even lead to loss of life and catastrophe.

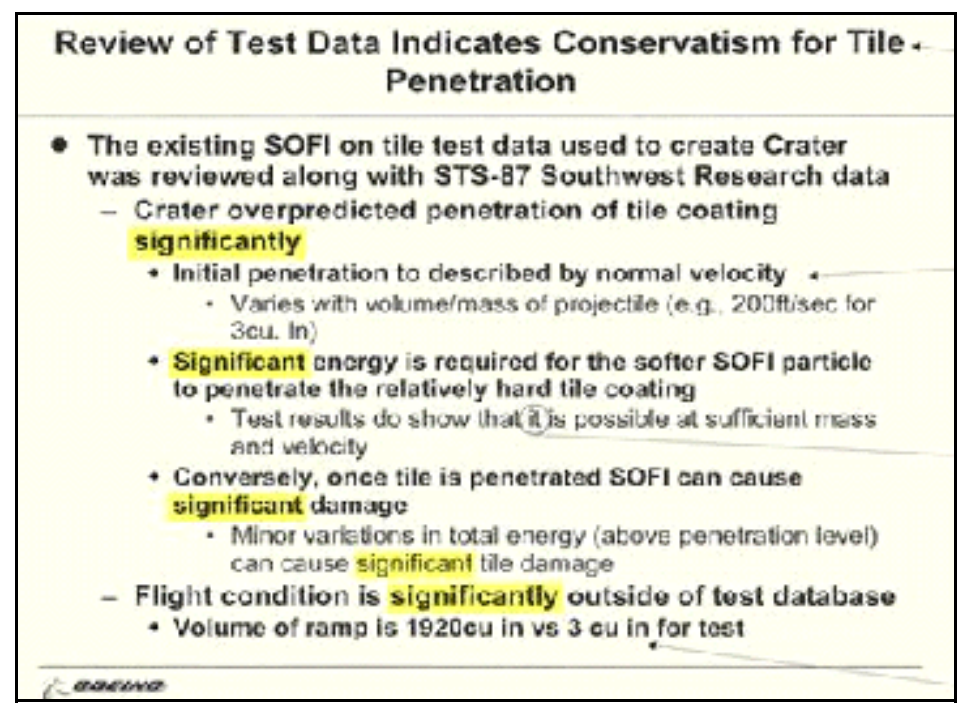

Figure 1. One of the PowerPoint slides prepared by Boeing engineers assessing possible damage from debris impact (Tufte, 2003). 
This was the case of the crash of the Columbia space shuttle in January 2003. As expected, the ship's foam insulation was finally found to be the main cause of the disaster. However, the wing damage by a $760 \mathrm{~g}$ piece of foam insulation happened twelve days before the space shuttle's fatal re-entry. When NASA engineers assessed possible wing damage during the mission, they presented the findings in a confusing PowerPoint slide, so crammed with nested bullet points and irregular short forms that it was nearly impossible to untangle the most important aspects of the message.

The senior managers received the set of PowerPoint slides and read them, but because of the way the information was presented, they did not realize that they addressed a lifethreatening situation. Measures could have been taken and perhaps the lives of the crew saved if the information had been clearly presented so as to underline the threat to human life. Although this is a rather extreme example, it is a phenomenon that occurs every day though without such severe consequences.

\subsubsection{Writing acceptable English}

If writing in English were not a sufficiently daunting hurdle in the obstacle race to academic renown, it is also necessary to write acceptable English. Otherwise, journals with a high impact factor will not publish one's article. As many engineers and scientists have learned to their dismay, having an acceptable command of the terminology in one's field and being able to read and speak English reasonably well does not guarantee the ability to create effective written texts in the language. Even native English users have problems with text organization and grammar.

When an article is rejected or sent back primarily because of poor linguistic expression, this often produces a sensation of astonishment laced with disbelief. The authors think that they have carried out an important study over a long period of time; they have obtained results despite inadequate funding; they have even gone to the trouble of presenting the research in English. How could their paper be rejected for something of such little importance as a few linguistic errors? After all, they reason, the text has basically the same form and structure that was used for successful oral presentations at international conferences. Couldn't the journal staff edit the article a little, clean up the text a bit, and leave the poor authors in peace after all the work that they have done?

Unfortunately, when an article is rejected for language reasons, a great many changes are often necessary at all levels of the text. As previously mentioned, oral and written presentations are different kinds of discourse, and each has its own rules. A rejected article may need modifications in discourse structure, syntax, vocabulary, pragmatic content, or a combination of all of these elements. Depending on the condition of the article, it may require anything from a short visit to the doctor's office to a prolonged stay in the intensive care unit or even CPR or mouth-to-mouth resuscitation.

Notorious aspects of English writing style that ELF users can find difficult are the use of verb tenses, definite and indefinite articles, the choice of prepositions, and punctuation, among other things. In oral communication, such problems can be compensated by other factors. If the person is a speaker with good presentation skills, grammatical errors are rarely 
obstacles for the effective transmission of a message.

However, when it comes to creating a written text, a wide variety of rules must be adhered to at all levels of the text. ELF users may not be aware, solely from their experience as readers, of the nuances that need to be observed. Lacking any other reference, they have a tendency to apply the notions of acceptability in their primary language to English with poor results.

For example, Spaniards often have a tendency to use very complex and baroque constructions. Although such sentences may work well in Spanish and be totally acceptable, in English the effect is precisely the opposite. To make matters worse, this type of formal sentence structure with many subordinate clauses generally clashes head-on with the author's indiscriminate use of terms such as "nowadays", verb contractions such as "don't", and phrases such as "to sum up" or "in a nutshell", all of which are informal.

Practice in writing research articles helps students to become accustomed to adapting the results of their work to a standardized written format and using the most appropriate terminology and phrases in order to communicate more effectively. This is a skill that is evidently useful in many other contexts as well.

\section{Conclusions}

The widespread use of English as an international language and as a tool of communication at a supranational level has transformed the language into a new variety of English, known as English as a Lingua Franca (ELF). Despite fears to the contrary, ELF is not detrimental to plurilingualism as part of the European identity because it provides the context where people speaking different national languages can interact with each other and exchange knowledge. This is especially true in the university context, where English-medium teaching affords the means for universities in different countries to create joint masters and doctorate programmes, and for postgraduate students to thus obtain the best of all possible worlds.

However, ELF is especially crucial as a communication tool in certain disciplines. In no professional area is the use of English more necessary for the cross-fertilization and transfer of knowledge than in science and technology. For this reason, engineers and scientists should acquire communication skills pertaining to knowledge in their respective fields. If they wish to be competitive, they must publish their research and disseminate their findings in English.

As previously mentioned, communicative competence in scientific and technical communication goes far beyond a certain fluency in the language. Rather, it also means an understanding of other aspects of communication such as how to vary intonation, rhythm, and sentence structure to argue one's viewpoint, and present content in such a way as to interest and persuade an audience. It signifies an understanding of the differences between oral and written communication, the contexts of scientific and technical interaction, and the texts that are typical of each context.

Finally, courses in scientific and technical communication should be a priority in polytechnic universities and engineering schools. Such courses should be tailored to the specific needs of the students, who live in an increasingly competitive world, and who will 
one day need to describe, present, and defend their ideas, work, and research in English.

\section{Notes}

1. This research has been carried out in project FFI2008-06080-C03-01/FILO, funded by the Spanish Ministry of Science and Innovation.

\section{References}

Alcón Soler, Eva (2007): "Linguistic unity and cultural diversity in Europe: implications for Research on English language and learning”. In E. Alcón Soler and M. P. Safont Jordà, eds., Intercultural Language Use and Language Learning, Dordrecht: Springer, 23-40.

Asimov, Isaac (1948/1972): "The endochronic properties of resublimated thiotimoline". In The Early Asimov. Vol. 3. Frogmore, St. Albans, Herts: Panther, 111-122.

Crystal, David (1997): The Cambridge Encyclopaedia of Language. Second Edition, Cambridge: Cambridge University Press.

Graddol, David (2001): "English in the future". In A. Burns and C. Coffin, eds., Analysing English in a Global Context: a Reader. New York: Routledge, 26-37.

House, Julian (2003): "English as a lingua franca: A threat to multilingualism?" Journal of Sociolinguistics 7: 556-579.

Hüllen, Werner. (2003): "Identifikationssprachen und Kommunikationssprachen". Zeitschrift für Germanistische Linguistik, 20/3: 298-317.

Johnson, Nicole (2005): “Communication breakdown?” The Scientist. [http://www.the-scientist.com/blog/display/75/ ].

Phillipson, Robert (2003): English-Only Europe? Challenging Language Policy. London: Routledge.

Pölzl, Ulrike. (2003): "Signalling cultural identity: the use of L1/Ln in ELF". View $[z]$ - Vienna English Working Papers 12/2: 3 - 23.

Smith, Larry. E. (1992): "Spread of English and matters of intelligibility". In B.B. Kachru, ed., The Other Tongue: English across Cultures. Urban/Chicago: University of Illinois Press, 75-90.

Stewart, Matthew (2004): Monturiol's Dream: The Extraordinary Story of the Submarine Inventor who wanted to Save the World. Frogmore, St. Albans, Herts: Panther

Tufte, Edward (2003): The Cognitive Style of PowerPoint. Cheshire, Connecticut: Graphics.

Wächter, Bernd (2008): "Teaching in English on the rise in European higher education". International Higher Education, no. 52.

[http://www.bc.edu/bc_org/avp/soe/cihe/newsletter/Number52/p3_Wachter.htm]. 